\title{
A formação do parque elétrico paulistano: relações de conflito entre a Companhia Água e Luz do Estado de São Paulo, seus clientes e seus concorrentes - 1890-1910.
}

Alexandre Ricardi

\section{Resumo}

Este artigo representa um pequeno excerto da pesquisa desenvolvida como iniciação científica do curso de graduação em História pela FFLCH - USP. Com a orientação do Prof. Dr. Gildo Magalhães dos Santos, faz parte do Projeto Eletromemória, que reúne pesquisadores das principais universidades de São Paulo para um estudo sobre o potencial historiográfico, arquivístico, museológico, bibliográfico e arquitetônico em empresas públicas e privadas do setor de energia elétrica paulista. Gostaríamos de agradecer ao professor Gildo pela orientação e à Fundação Patrimônio Histórico da Energia e Saneamento, Núcleo de Documentação e Pesquisa, onde está custodiado o fundo da Companhia Água e Luz, e onde desenvolvemos este estudo, pela gentileza no atendimento e presteza nas informações.

Palavras chave: Eletricidade, Primeira República, São Paulo 
A formação do parque elétrico paulistano: relações de conflito entre...

Neste artigo procuramos analisar a atuação da Companhia Água e Luz do Estado de São Paulo, ao contrário da maioria dos estudiosos da formação do setor elétrico em São Paulo, que analisam a atuação da The Sao Paulo Tramway, Light and Power, tais como José Antônio Segatto, Ricardo Maranhão, Edgard Carone, José Alfredo Vidigal Pontes, justamente devido à característica relação que a Light and Power cedo estabeleceu em São Paulo e com suas elites dirigentes. A nossa opção se deveu justamente por ser a Companhia Água e Luz representante de capital nacional, ao contrário da Light and Power; por ter se formado e instalado em São Paulo cerca de dez anos antes da empresa anglo-canadense-americana; por ter utilizado matriz energética térmica e não hidráulica, e por ser representante também do mercado de livre concorrência, que se instalava na Primeira República. A Companhia Água e Luz do Estado de São Paulo foi também pivô de disputas que culminaram no monopólio do setor, detido pela Light and Power pelos próximos 80 anos, a partir de mais ou menos I909, caracterizando-se a Companhia Água e Luz como objeto de estudo, bastante adversa da Light and Power.

A bibliografia consultada dá conta com competência do desenvolvimento da história da formação do parque elétrico no Brasil, e principalmente em São Paulo. Praticamente ignora, entretanto, a Companhia Água e Luz, que teve alguma atuação nesta história, com o fornecimento do serviço não só em São Paulo, mas também em Curitiba e em Casa Branca, cidade do interior paulista. Informações desencontradas são fornecidas nas publicações sobre o curto período de atuação da companhia, não existindo consenso sobre pontos importantes. Preferimos, então, interrogar os poucos documentos relativos a essa companhia e esse período, exercitando a função de historiador tal qual Marc Bloch tão bem defendeu em seu Apologia da História, demonstrando que realmente "o conhecimento do passado é coisa em progresso, que ininterruptamente se transforma e se aperfeiçoa".

Sendo assim, abordamos como foi absorvida a tecnologia e como se deu o desenvolvimento do parque elétrico em São Paulo, a partir da história de uma empresa, suas relações com as demais companhias, seus clientes e a própria história de São Paulo. Permitindo-nos analisar, então, como se desenrolou parte importante do próprio desenvolvimento da cidade e deste setor que passou a ganhar cada vez mais importância na vida do homem moderno, mormente o paulistano.

Ainda que fosse tecnologia estrangeira, importada que era, os brasileiros conseguiram dominar as técnicas para sua produção e distribuição, sofisticando cada vez mais seu fornecimento e consumo, processo parecido com o que ocorreu com as ferrovias, construídas por engenheiros ingleses. ${ }^{2}$ Esse processo

I BLOGH, Marc, p. 55 .

2 VARGAS, Milton, p. 37. 
de transferência de tecnologia representa uma "aquisição que realmente requer esforço próprio de todos os integrantes do processo de produção, esforço do qual o Brasil em muitos setores resolveu abdicar, entregando-se ao domínio estrangeiro"3, redundando em lentidão para ser concretizado. Até porque, como declarou alto funcionário norte-americano em 1975, "se quisermos manter nossa liderança, devemos preservar nossa tecnologia, vender produtos e não know-how", 4 demonstrando bastante bem porque a transferência pode ser extremamente difícil de ser cedida pelos países que dominam as tecnologias.

\section{A Companhia Água e Luz do Estado de São Paulo}

Em I886, a firma Marques, Multai \& Company organizou a Empresa Paulista de Eletricidade, cuja operação foi iniciada em I888 com quatro geradores Ganz, de Budapeste, dois de $50 \mathrm{kVA}$ e dois de $200 \mathrm{kVA}$, num total de $500 \mathrm{kVA}$, em usina térmica alimentada a carvão, situada na rua Araújo, próximo à praça da República. Seu fornecimento limitava-se ao período do entardecer à meianoite ${ }^{5}$ e sua concessão cobria a área correspondente ao triângulo comercial da capital, à época ainda a principal região da cidade.

Muitas controvérsias se apresentam entre a bibliografia especializada no período quanto ao exato momento em que a Empresa Paulista de Eletricidade foi adquirida pela Companhia Água e Luz do Estado de São Paulo. Em nossas pesquisas junto ao fundo da Companhia Água e Luz, custodiado no Núcleo de Documentação e Pesquisa da Fundação Energia e Saneamento, não encontramos indícios de como o início das operações da empresa se deu. Fato é que uma apólice de seguros da companhia é datada de 25 de setembro de I89I. Nela, a Companhia de Seguros Marítimos e Terrestres Argos Paulista segura o material do escritório da Água e Luz situado à rua do Rosário, $\mathrm{n}^{\mathrm{O}} 2$, em três contos de réis, contra os riscos de incêndio, raio e suas consequências. ${ }^{6}$

O combustível utilizado pela Água e Luz em suas usinas de São Paulo e de Casa Branca era de preferência o carvão, em I898. E em um flagrante contraste do tamanho e do consumo das duas usinas, a companhia gastou onze contos, seiscentos e oitenta e quatro mil réis (II.684\$OOO) para a compra de carvão para São Paulo e um conto, setecentos e setenta e dois mil réis (I.772\$OOO) para Casa Branca. ${ }^{7}$

3 MIROW, Kurt Rudolf, p. I9.

4 MIROW, Kurt Rudolf, p. 22.

5 SILVA, José Luiz M. da, p. I5.

6 Apólice de Seguros no II47, de 25 de setembro de I89I, Fundo Água e Luz.

7 Balancete em 3I de janeiro de I898, Fundo Água e Luz, Fundo Água e Luz. 
A formação do parque elétrico paulistano: relações de conflito entre...

São maiores ainda as divergências quanto ao período em que a Água e Luz passou a ser controlada pela Light and Power. Devido a problemas internos de caixa e à fortíssima concorrência da canadense, lembramos que a Água e Luz já fazia e sofria concorrência da San Paulo Gas Company. A empresa tentou vender seus ativos, sem sucesso, conforme observamos:

\begin{abstract}
"temos, sem o mínimo resultado, envidado todos os esforços para vender os materiais adquiridos pela companhia para o estabelecimento da luz elétrica nas cidades de Curitiba, Estado do Paraná, e de Casa Branca, neste Estado; bem como os materiais nesta Capital existentes, para o que pela imprensa e por muito tempo chamamos concorrentes. Entretanto, ao passo que seus esforços são improfícuos, a situação da companhia dia a dia se torna mais grave, antepondo-se a esses esforços as questões judiciais, que naturalmente nascem de semelhante situação". ${ }^{8}$
\end{abstract}

As divergências entre os especialistas desse período continuam quanto ao exato momento em que entra em cena o grupo fluminense Guinle \& Cia. Neste caso, somos apresentados ao grupo pelo historiador e ex-professor do Departamento de História da Universidade de São Paulo, Edgar Carone que, por meio de dois artigos na publicação Memória do Departamento de Patrimônio Histórico da Eletropaulo, ${ }^{9}$ nos traz a novidade do grupo como acionista majoritário da Água e Luz, tornando-se, então, as concessões que esta detinha na cidade de São Paulo pivô de contínuas disputas que se estabelecem entre o grupo canadense e o grupo do Rio de Janeiro até I909, disputas estas que serão mais bem expostas em outra ocasião.

Em contraposição, Roberto Antônio Iannone ${ }^{\mathrm{IO}}$ nos apresenta a data de I899 para a absorção da Companhia Água e Luz pela Light and Power. A carta patente da Light and Power foi concedida pela rainha Vitória da Inglaterra, em 7 de abril de I899, e fixada na sua sede em Toronto, Canadá. O curto espaço de tempo que a Light and Power teve para se organizar, começar a atuar na cidade de São Paulo e já iniciar o processo de compra e venda de outras empresas não é de estranhar, se imaginarmos que negociações já eram feitas por Américo e Carlos de Campos no sentido de repassar para empresas estrangeiras as concessões para explorar o serviço de viação a tração elétrica que o sogro de Carlos, Antonio Augusto de Souza, detinha desde I897. ${ }^{\text {II }}$

8 Reunião de acionistas, sem data, Fundo Água e Luz.

9 CARONE, Edgar. Light Versus Guinle e A mobilização social no conflito Light X Guinle.

IO IANNONE, Roberto A, p. 34 .

II SOUZA, Edgard Egydio de, p. 32. 
Neste mesmo ano, a Light and Power, ainda com o Railway em seu nome, ${ }^{12}$ realiza os primeiros estudos para a implantação da tração pública por eletricidade em São Paulo, entrando realmente em operação em 7 de maio de I900, ${ }^{13}$ quando é inaugurada com grande comemoração a primeira linha eletrificada de bonde, conforme trechos de reportagem a seguir reproduzidos. Esta linha fazia o percurso Barão de Limeira - Largo de São Bento, serviço este alimentado por usina térmica, construída rapidamente na rua São Gaetano:

Realizou-se ontem, como estava anunciada, a inauguração da linha da São Paulo Railway, Light and Power Company, do largo de S. Bento à Barra Funda.

Às 12 horas e 35 minutos da tarde partiram da frente do escritório da Companhia, à rua Direita, 7, vários carros, [a] caminho da usina da rua Monsenhor Andrade, esquina da rua de S. Caetano, conduzindo os diretores da empresa, senadores, deputados, representantes da imprensa e muitos convidados.

À I hora da tarde chegaram todos às grande oficinas da Light and Power afim de ser dado andamento nos maquinismos ali assentados, para transmissão de luz e força, achando-se nessa ocasião presentes os srs. Drs. Rodrigues Alves e Domingos de Moraes, presidente e vice-presidente do Estado, e o ajudante de ordens, capitão Marcondes, e um representante do Estado de S. Paulo.

À I hora e 25 minutos da tarde o dr. Rodrigues Alves, a convite dos srs. Robert Brown e James Mitchell, aproximou-se do motor principal da usina e, puxando uma alavanca, pôs em movimento a máquina. Em seguida dirigiu-se para junto do quadro de distribuição de eletricidade e ali fechou o circuito de excitação do dínamo, ligando a corrente geral com a linha.

[...]

Os bonds tinham pendentes dos balaustres festões de folhagem e flores, tremulando nas alavancas de comunicação com os cabos aéreos a bandeira nacional.

[...]

Por todo o trajeto aglomerava-se enorme multidão, nas esquinas portas e janelas, aclamando, a espaços, a empresa, com vivas e palmas, à passagem dos veículos, apinhados de passageiros.

De volta do extremo da alameda Barão de Limeira pararam de novo os bonds à frente do depósito, onde foi servido aos membros do governo e convidados um lauto lunch, tomando assento, no lugar de honra da mesa, o dr. Rodrigues Alves, que tinha

I2 Em 25/07/1900 a Light and Power foi autorizada por decreto federal a mudar sua razão social de The São Paulo Railway, Light and Power Company para The São Paulo Tramway, Light and Power Company a fim de evitar conflitos jurídicos com a The São Paulo Railway Company, empresa fundada pelo barão de Mauá em I855, responsável pela construção, em I867, da estrada de ferro Santos - Jundiaí, conhecida à época como a Ingleza. I3 SOUZA, Edgard Egydio de, p. 55. 
A formação do parque elétrico paulistano: relações de conflito entre...

ao lado os srs. Domingos de Moraes, Antonio Prado, Candido Rodrigues, Francisco Malta e Robert Brown, superintendente da empresa.

Ao dessert levantou-se o dr. Carlos de Campos, que, em nome da São Paulo Railway, Light and Power Company, brindou o dr. Presidente do Estado e prefeito municipal.

O dr. Antonio Prado, usando em seguida da palavra, referiu-se com entusiasmo ao grande melhoramento de que acaba de ser dotada a capital, terminando por fazer votos pela prosperidade da empresa americana.

[...]

O dr. Mackenzie, da Light Power saudou a imprensa, respondendo-lhe o dr. Luiz Piza, que agradeceu e saudou a companhia na pessoa do dr. Brown. [... $]^{\text {I4 }}$

A concessão para explorar os serviços de viação movida a tração elétrica foi cedida na cidade de São Paulo pela Câmara Municipal através da lei n ${ }^{0} 304$, de I5 de junho de I897 por quarenta anos a Francisco Antônio Gualco, capitão da Marinha italiana, e ao sogro de Carlos de Campos, Antônio Augusto de Souza. A transferência desta concessão e seus privilégios para a Light and Power se deu em 28 de dezembro de I899, cinco meses após o ministro da Indústria, Viação e Obras Públicas, Severino Vieira, autorizar o funcionamento da companhia canadense, por intermédio do Decreto $\mathrm{n}^{\mathrm{O}} 3 \cdot 349 \cdot{ }^{\mathrm{I}}$

Um dos mais ativos agentes para o estabelecimento da Light and Power no Brasil, Carlos de Campos (I866-I927) ${ }^{16}$ teve destacada atuação nas negociações, sendo hábil político, senador em I9I5 e presidente do Estado de São Paulo de I924 a I927. Era membro de uma família de políticos e negociantes como seu tio, Américo de Campos e seu pai, Bernardino de Campos, também presidente do Estado no início da primeira República. Advogado e lobista da Light and Power desde sua formação em I899, Carlos de Campos foi talvez uma das melhores representações da união do capital estrangeiro, interessado cada vez mais por atuar na economia brasileira, com a oligarquia cafeeira do Estado.

Exemplifica tão perfeitamente uma espécie de relação com os estrangeiros e o capital, tão típica dos trópicos e criticada por Sérgio Buarque de Holanda quando demonstra porque sofre tanto o capitalismo em prosperar em terras tupiniquins. ${ }^{17}$ Sem enveredarmos por esta questão, notamos que Carlos de Campos nos deu outro exemplo de típicas relações quando, sempre em nome da Light and Power, em I905 atuou como um dos negociadores da fundação do jornal A Gazeta,

I4 O Estado de São Paulo, o8 de maio de I900.

I5 SOUZA, Edgard Egydio de, p. 32.

I6 Enciclopédia Mirador Internacional, p. I970.

I7 BUARQUE DE HOLANDA, Sérgio, pp. 49-56. 
veículo de comunicação utilizado para a defesa dos interesses da canadense, ${ }^{18}$ assunto que será mais bem tratado em outra ocasião também. Feito este realizado em associação com o financista Percival Farquar, dono de biografia polêmica, protagonista dos casos Itabira Iron e da construção da ferrovia Madeira-Mamoré. ${ }^{19}$

Para a Companhia Água e Luz, entretanto, a opção de fornecer energia por intermédio de uma usina a vapor, utilizando como combustível óleo, madeira ou carvão, manteve-a sempre diante de custos altos e retorno incerto no negócio. Analisando a trajetória da companhia, concordamos que a geração termelétrica implicaria limitação ao desenvolvimento do setor elétrico paulistano, pelo menos enquanto os combustíveis utilizados fossem os apontados, não resultando necessariamente em comprometimento do crescimento coordenado deste setor. A Constituição de I89I outorgava aos municípios e Estados a prerrogativa de legislar sobre o assunto, imprimindo um caráter eminentemente local da implantação $e$ do desenvolvimento do parque elétrico. ${ }^{20}$ Não suportando então a concorrência de empresas, no caso a Light and Power, que chegaram ao mercado brasileiro com a proposta de fornecer energia baseada na hidroeletricidade.

Os custos de construção de usinas hidrelétricas não são, entretanto, mais baixos do que para construir e manter uma usina térmica. A própria Companhia Água e Luz cogitou na adoção do fornecimento baseado na energia hidráulica, conforme verificado em relatório da diretoria:

A diretoria fez o maior empenho para transformar a nossa força por força hidráulica, comprou uma parte da cachoeira do Rasgão e segurou por uma escritura de compromisso de compra a cachoeira de Pau d'Alho. Recebeu orçamento de várias casas da Europa, porém as dificuldades de levantar capital preciso foram enormes, apenas conseguimos dois mil contos, quando precisávamos de treze mil. ${ }^{21}$

Um dos principais problemas, então, que percebemos, foi a incapacidade de levantar os fundos necessários para a implantação da ideia, pois "a geração, transporte e distribuição de eletricidade constituem-se em atividades consideravelmente intensivas no uso de capital, exigindo elevados investimentos e englobando ativos muito específicos, que usualmente, não são exigidos em muitos outros segmentos produtivos". ${ }^{22}$ Reiteramos que as dificuldades apresentadas

I8 SOUZA, Edgard Egydio de, p. 35 e PONTES, José Alfredo V., p. 63-66.

I9 Retrato do Brasil, I9 de novembro a 2 de dezembro de I987.

20 LIMA, José Luiz M. da, p. I5.

2I Relatório da Diretoria da Companhia de Água e Luz do Estado de S. Paulo que tem de ser apresentado à Assembleia Geral Extraordinária convocada para hoje, 3I de Maio de I900, Fundo Água e Luz. 22 IANNONE, Roberto A, p. 22. 
A formação do parque elétrico paulistano: relações de conflito entre...

não nos levam a acreditar que o movimento, que aconteceu posteriormente, de monopolização do setor sob o controle de poucas companhias, em São Paulo, duas estrangeiras, a Light and Power e a Amforp, era inevitável.

Não ignoramos a existência de outras companhias, de caráter local e que resistiram ao "abraço" das estrangeiras, que engendraram o monopólio de forma bem articulada com os poderes políticos locais. Em I90I, a Companhia Água e Luz do Estado de São Paulo tinha I.048 consumidores, sendo a maioria de clientes comerciais. ${ }^{23}$

\section{Curitiba e Casa Branca: maus clientes?}

Associada a todas as dificuldades já enfrentadas, os problemas que surgiram entre a Companhia Água e Luz e seus clientes consumidores foram decisivos em sua trajetória. AÁgua e Luztinha entre seus clientes as Câmaras Municipais de Curitiba, no Paraná, e Casa Branca, em São Paulo. O momento exato desta expansão para fora da cidade de São Paulo não pôde ser reconstituído, provavelmente se deu por compra da concessão já detida por alguma companhia nestas duas cidades. Revela, porém, uma razoável capacidade de articulação e organização de uma companhia com reduzido capital nacional e se não logrou êxito nesta trajetória, sua responsabilidade pode ser minimizada, como veremos adiante.

As Câmaras Municipais representavam não só importantes clientes, com potencialidade de consumo bastante considerável, além de representarem também um excelente cartão de visitas para a Água e Luzem diferentes localidades. Todavia, não só tornaram-se inadimplentes, como contribuíram para o aumento dos custos da Companhia, como pudemos perceber pela correspondência mantida com Rudolf Zinneck, representante da Companhia em Curitiba:

A Câmara, parece-me, que de propósito não faz mais os pagamentos pontualmente, pois recebo, por exemplo, hoje um conto, depois de oito dias outro ou um pouco mais ou também às vezes só 500.000 rs afinal que, quando pagam uma prestação de um mês também já outro está vencida. Em novembro prometeu saldar todas as contas restantes, porém quando chego lá para receber nunca há dinheiro. ${ }^{24}$

Os custos do fornecimento eram aumentados quando os clientes obrigavam a Água e Luz a processá-los, custos judiciais, ou os impunham à sua revelia, como fizera a Câmara de Curitiba em I897:

23 Estação de força da Cia. Água e Luz do Estado de São Paulo, I9oI in SOUZA, Edgard Egydio de, p. 4I.

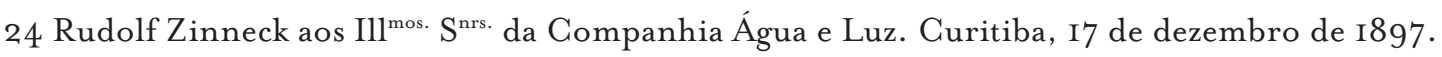


A Câmara está muito descontente com a Companhia. Em vez de anular o contrato, multou a Companhia por um conto, dando Io dias de prazo para inteiro cumprimento do contrato. Me disseram que querem continuar a multar até a Companhia ou resolver vender a instalação ou estar tudo de conformidade [com o] contrato, que para eles seria igual, se não é esta, é outra Companhia que fornece-lhes luz e que em todo caso estão pagando a iluminação caro demais. ${ }^{25}$

A querela com a Câmara Municipal de Curitiba arrastou-se de forma quase diplomática, aparentemente a Água e Luz preocupou-se em conservar este cliente e evitou agir de forma brusca nesta questão. Já a contenda com a Câmara Municipal de Casa Branca, ocorrida alguns anos antes, fora resolvida de outra forma e a própria Câmara se manifestou à Companhia Água e Luz:

Declaro-vos que só hoje foi a Câmara Municipal intimada do protesto requerido pela Companhia Água e Luz do Estado de São Paulo, da qual sois digno Presidente. A Câmara nunca se negou e nem se nega ao pagamento dos juros de $9 \%$ ao ano, devido pelas prestações atrasadas, conforme preceitua o artigo $4^{\circ}$ do contrato.

Dentro em poucos dias deverá reunir-se em sessão a Câmara Municipal e nessa ocasião tomará conhecimento do protesto e da rescisão do contrato, feito por essa Companhia. Antecipadamente posso informar-vos de que a Câmara não deixará correrem à revelia os seus direitos e reclamará por todas as faltas cometidas por essa Companhia, no cumprimento do seu contrato. ${ }^{26}$

Em reunião de acionistas, em abril de I90o em São Paulo, a questão foi mencionada, e se nos atentarmos às datas indicadas, observaremos o quanto a questão se arrastou nos tribunais e podemos especular o quanto não custou à Água e Luz,

A questão que a Companhia mantinha no Foro desta Capital com a Municipalidade de Casa Branca foi decidida a nosso favor em primeira instância, sendo de esperar a confirmação da sentença. ${ }^{27}$

A potencialidade de tão reduzido mercado como devia ser o de Casa Branca, porém, é percebida claramente quando a própria Companhia Água e Luz cancelou seu contrato com a Câmara Municipal de Casa Branca e não faltaram interessados em substituí-la no fornecimento,

25 Rudolf Zinneck aos Illmos. Snrs. da Companhia Água e Luz. Curitiba, I7 de agosto de I897. 26 Protesto da Câmara Municipal de Casa Branca, 9 de fevereiro de I892, Fundo Água e Luz. 27 Reunião de acionistas de 2I de abril de I900, Fundo Água e Luz. 
A formação do parque elétrico paulistano: relações de conflito entre...

Informado de que o serviço de iluminação elétrica da cidade de Casa Branca foi interrompido pela Cia. de que sois mui digno Gerente, por motivo de falta de renda compensadora, e como me acho em condições especiais para explorar tal serviço, achando-me à testa da Empresa Força e Luz de Ribeirão Preto e explorando uma pequena instalação em Cravinhos, venho pedir-vos informações das condições técnicas da instalação elétrica da referida cidade, suas condições econômicas, contractos com a Câmara Municipal, prazo d'este, preços da iluminação particular etc., noticia sobre o motor, se ele é simples ou [ilegível], seu consumo médio de combustível e finalmente se a Companhia Água e Luz de S. Paulo está resolvida a aceitar uma proposta séria de arrendamento de tal serviço com todas as garantias possíveis que o caso exigir. ${ }^{28}$

As possibilidades de manobras dos clientes nos levam à questão do monopólio. Por diversas vezes, e os casos ilustrados o comprovam, a Companhia Água e Luz permanecia impotente diante da ação de seus clientes consumidores. Em um mercado controlado por poucas companhias, os consumidores perdem este espaço de manobra. Não defendemos, porém, que havia amplo espaço para o consumidor e o empregado se defenderem de maus fornecedores de serviços ou de maus patrões, muito ao contrário.

O Brasil de então, era país marcado pela insuficiência da legislação para que melhorasse as condições de trabalho, onde as oligarquias cafeeiras controlavam quase todos os segmentos econômicos e era muito difícil também para os consumidores reivindicarem direitos. A Primeira República se baseava num liberalismo excludente e autoritário, "ao mesmo tempo, em que dava garantias e segurança aos negócios e lucros das empresas nacionais e estrangeiras, o liberalismo oligárquico reafirmava a não-intervenção do Estado no mercado e nas relações de trabalho", ${ }^{29}$ reproduzindo o sistema marcado pela desigualdade social e econômica típica do Império, mudando apenas as personagens.

Os operários, porém, acabam se organizando antes dos empresários e em I890-I89I se forma um partido operário no Rio de Janeiro, então Distrito Federal e em Fortaleza. Em I896, era criado no Centro Socialista de Santos, o Partido Operário Socialista. Em contrapartida, a organização dos industriais empregadores em entidades patronais só se dará em I9I7, como reação à greve geral que aconteceu em São Paulo. ${ }^{30}$

A Câmara Municipal de Curitiba, entretanto, soube bem como agir em relação à Companhia Água e Luz. Parece que considerava outras possibilidades

28 Rufino A. de Almeida ao Sr. Pagani, Gerente da Companhia Água e Luz. Cravinhos, I2 de março de I899.

29 SEGATTO, José Antônio, p. 209.

30 LEVI-MOREIRA, Sílvia, p. I4. 
de fornecimento de energia, como informou Zinneck em I897, assim como negociou o fornecimento de luz elétrica sem prévia consulta à companhia, como informado nesta mesma missiva de I897.

Há pouco tempo também esteve aqui um engenheiro da firma Siemens e Halske em Berlim, para explorar a cascata da serra para fazer instalação de luz elétrica e fornecer forças com eletro motores. Ouvi dizer na Câmara que em princípio de I898 estaria pronta a instalação e que então a Câmara teria uma luz melhor??? ${ }^{3 \mathrm{r}}$

A Santa Casa de Misericórdia receberia luz elétrica por intermédio da Câmara, que custearia a instalação. O consumo, todavia, seria mantido à custa da Companhia Água e Luz, fato ainda inédito para o gerente Zinneck.

Estes dias falou-me também um cunhado do padre Alberto. O mesmo diz que tinha falado com o Snr. Dr. Machado para fazer-se instalação na Santa Casa de Misericórdia com 32 a 36 bicos, e que o último já tinha recebido resposta da Companhia para poder mandar fazer. Diz que será paga a instalação, porém o consumo a Companhia dará gratuito. Respondi que até agora não tinha recebido aviso da Companhia para fazer, e o Snr. Dr. Machado também ainda não me falou a respeito disto. ${ }^{32}$

O aparecimento de engenheiros estrangeiros da Siemens and Halske pode significar o quanto já era atraente o mercado elétrico brasileiro neste período para as empresas estrangeiras, que estavam inseridas num movimento de expansão capitalista sem precedentes até então, e que o país ainda não tinha condições para prospectar e desenvolver por si mesmo tal tecnologia.

Milton Vargas, ao se referir ao programa nuclear brasileiro dos anos 80, nos alerta que para um processo de transferência de tecnologia ser bem-sucedido, deve existir como intermediário uma organização de ensino e de pesquisa não comercial, "pois a tecnologia não é mercadoria que se vende e compra, mas sim, saber que se aprende". ${ }^{33}$ Faltava-nos, porém, sólidas organizações de ensino que pudessem absorver essa tecnologia estrangeira neste período que estudamos.

Em I890, é aprovado pelo Congresso norte-americano o Sherman Act, proibindo combinações e/ou acordos entre empresas que significassem o fim da livre concorrência, tentando eliminar o estabelecimento dos cartéis. ${ }^{34}$ Muitos outros atos são aprovados a partir de então, fechando cada vez mais

3I Rudolf Zinneck aos Illmos. Srs. da Companhia Água e Luz. Curitiba,o8 de março de I897. 32 Rudolf Zinneck aos Illmos. Srs. da Companhia Água e Luz. Curitiba, 8 de março de I897. 33 VARGAS, Milton, p. I28.

34 KUGINSKI, Bernardo, p. 53. 
A formação do parque elétrico paulistano: relações de conflito entre...

o cerco à cartelização do mercado norte-americano. Apesar de se preocupar mais especificamente com a marcha monopolizadora que vinha sendo realizada na área petrolífera, os norte-americanos acabaram atingindo as indústrias de forma geral, que passam a realizar movimentos de expansão de suas companhias para fora do território norte-americano, entre elas a poderosa General Electric Company.

A Siemens and Halske era já uma companhia com grande poderio de negociação, pois era grande fornecedora de materiais elétricos para diversas firmas do Brasil, como atestam muitos recibos da própria Companhia Água e Luz. Fundada em $\mathrm{I}^{\mathrm{O}} \mathrm{de}$ outubro de I847 com o nome Telegrafen-bauanstalt Siemens and Halske ${ }^{35}$ na Alemanha, por Werner von Siemens, a Siemens foi praticamente a única companhia do setor elétrico europeu que resistiu às fortes investidas da General Electric Company. Essa companhia norte-americana formada após a fusão das empresas de Thomas Edison e Elihu Thomson, que construiu centrais elétricas na Itália e tornou-se sócia dos maiores fabricantes de materiais elétricos da Grã-Bretanha, França e da Phillips holandesa, ${ }^{36}$ além de firmar um acordo sobre patentes já em I 896 com a Westinghouse, também norte-americana, tornou-se rapidamente uma gigante do setor elétrico. ${ }^{37}$

Assim, a formação do parque elétrico na cidade de São Paulo e uma pequena companhia de limitado capital nacional estão intimamente ligados a um vigoroso movimento de expansão capitalista que ocorreu ao final do século XIX. Analisarmos como esta e outras pequenas companhias que existiram pelo interior do Estado foram engolfadas neste movimento é de suma importância para compreendermos como este parque elétrico acabou monopolizado por praticamente apenas uma companhia. É senda importante também na trajetória para compreendermos como há poucos anos o parque elétrico mudou novamente por decisão governamental e porque exatamente segue o rumo que está seguindo.

35 MIROW, Kurt Rudolf, p. 34.

36 KUGINSKI, I984, p. 57.

37 MIROW, Kurt Rudolf, p. I9. 


\section{Referências bibliográficas}

BLOCH, MARG. Apologia da História. Trad. Maria Manuel Miguel e Rui Grácio. Lisboa, Publicações Europa-América, I965. Coleção Saber.

CARONE, Edgar \& DÉR, Rosa Maria. Light versus Guinle, in Memória, ano II, n. ${ }^{\circ}$ 3, abril/maio/junho de I989.

COSTA, Marcos (org.). Para uma nova história, textos de Sérgio Buarque de Holanda. São Paulo: Fundação Perseu Abramo, 2004.

História e energia: a chegada da Light. n. ${ }^{\circ}$ I. São Paulo, Patrimônio Histórico/Eletropaulo, I986.

História e energia: a eletrificação no Brasil. n. ${ }^{\circ}$ 2. São Paulo, Patrimônio Histórico/Eletropaulo, I986.

História e Energia: A Light e a revolução de 24. n. ${ }^{\circ} 4$. São Paulo. Patrimônio Histórico/Eletropaulo. I986.

HOLANDA, Sérgio Buarque de. Raizes do Brasil. Pref. de Antônio Cândido. $4 \cdot{ }^{\mathrm{a}}$ ed. Brasília: Universidade de Brasília, I963.

IANNONE, Roberto. Evolução do setor elétrico paulista. Tese apresentada ao curso de pós-graduação em História Econômica do Departamento de História da FFLGH-USP, para obtenção do título de Doutor. 2006.

KUCINSKI, Bernardo. O que são multinacionais. $6 .^{\mathrm{a}}$ ed. São Paulo: Brasiliense, I984.

LEVI-MOREIRA, Sílvia. São Paulo na primeira República: as elites e a questão social. São Paulo: Brasiliense, I988.

MÁXIMO DA SILVA, João Luiz. O impacto do gás e da eletricidade na casa paulistana (1870-1930). Dissertação apresentada ao curso de pós-graduação em História Social do Departamento de História da FFLGH-USP, para obtenção do título de Mestre em História. 2002.

MIROW, Kurt Rudolf. A Ditadura dos Cartéis. Anatomia de um subdesenvolvimento. Rio de Janeiro: Givilização Brasileira, I977. Retratos do Brasil, Vol. IO2. 
A formação do parque elétrico paulistano: relações de conflito entre...

PONTES, José Alfredo O. V. A Light e a Imprensa. In Memória Eletropaulo. São Paulo, jul./dez. I995. N. ${ }^{\circ} 22$.

SEGATTO, José Antônio. A República e a Light. In Memória, ano II, n. ${ }^{\circ}$ 2, janeiro/ fevereiro / março de I989.

SOUZA, Edgar Egydio de. História da Light-Primeiros 50 anos. 2. a ed. revista e ampliada. São Paulo: Departamento do Patrimônio Histórico / Eletropaulo, I989.

VARGAS, Milton. História da ciência e da tecnologia no Brasil: uma súmula. São Paulo: Humanitas / FFLCH / USP: Centro Interunidade de História da Giência, $200 \mathrm{I}$.

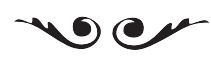

Alexandre Ricardi é graduando em História pela USP.

E-mail: alexandre.ricardi@usp.br 